\title{
Effect of Si addition on microstructure and mechanical properties of $\mathrm{Al}-\mathrm{Mg}-\mathrm{Si}$-Zn alloy
}

\author{
Fan-bo Meng', *Hong-jun Huang ${ }^{1}$, Xiao-guang Yuan', Ze-wen Cui ${ }^{2}$, Xian-lei Hu ${ }^{\mathbf{3}}$ \\ 1. School of Materials Science and Engineering, Shenyang University of Technology, Shenyang 110870, China \\ 2. School of Materials Science and Engineering, Liaoning Technology University, Fuxin 123000, China \\ 3. State Key Laboratory of Rolling and Automation, Northeastern University, Shenyang 110004, China
}

\begin{abstract}
The effect of Si addition on the microstructure and mechanical properties of Al-Mg-Si-Zn aluminum alloys were investigated. Results show that the microstructure of Al-Mg-Si-Zn alloy with low Si contents is mainly composed of $\mathrm{Mg}_{2} \mathrm{Si}$ and $\mathrm{Mg}_{5} \mathrm{Si}_{6}$ phases. With the increasing of $\mathrm{Si}$ content, $\mathrm{Si}$ and $\mathrm{Al}_{3.21} \mathrm{Si}_{0.47}$ phases precipitate in the form of eutectic phases in the alloys, at the same time, the mean shape factor of the second phase firstly increases and then decreases. Regression analysis results show that the Si content has the main influence and the mean shape factor has the least influence on tensile strength. Tensile strength increases significantly with the addition of $\mathrm{Si}$, however, there is a remarkable drop in the elongation of the alloys. Decreased elongation is related to the formation of monotonous $\mathrm{Al}$ (200) structure and the enlargement of interplanar spacing of (111) and (200) crystalline planes.
\end{abstract}

Key words: Si content; mean shape factor; area fraction; tensile strength; aluminum alloy

CLC numbers: TG146.21 Document code: A

Article ID: 1672-6421(2020)01-015-06

$\mathrm{T}$ he Al-Mg-Si alloys are heat-treatable materials, widely employed in the automotive industry, aerospace, and other fields, due to characteristics such as medium strength, low specific strength/stiffness, high formability, good weld ability, low cost, and high corrosion resistance ${ }^{[1,}$ ${ }^{2]}$. The relative content of $\mathrm{Mg}$ and $\mathrm{Si}(\mathrm{Mg} / \mathrm{Si})$ were widely recognized for having an influence on the microstructure, mechanical properties and precipitation behavior of $\mathrm{Al}$ alloys ${ }^{[3-6]}$. Additionally, the presence of excess Si would promote the precipitation of uniform and fine-grained $\beta^{\prime \prime}$ phases, improving the age hardening response of the alloy. However, the excessive $\mathrm{Mg}$ content would reduce the stretching formability, make the 6xxx alloys exhibit low strength but excellent corrosion resistance ${ }^{[7,8]}$. Some elements, such as $\mathrm{Mn}, \mathrm{Cu}$ and $\mathrm{Cr}$, are added as microstrengthening elements of Al-Mg-Si alloys ${ }^{[9-11]}$.

$\mathrm{Al}-\mathrm{Mg}-\mathrm{Si}-\mathrm{Zn}$ alloys are considered as the most promising candidates for automotive materials. The solid solubility of $\mathrm{Zn}$ in $\mathrm{Al}$ is $82.8 \mathrm{wt}$ \% at eutectic temperature, and $\mathrm{Zn}$ atoms can combine with $\mathrm{Mg}$ forming plate-like semi-coherent $\eta^{\prime}$ metastable precipitates and equilibrium $\eta-\mathrm{MgZn}_{2}$ precipitates on

\section{*Hong-Jun Huang}

Male, Ph.D, Professor. His research mainly focused on composition design and forming technologies of aluminum and titanium alloys.

E-mail: huanghong1977@163.com

Received: 2019-09-11; Accepted: 2019-11-12
(111)Al planes ${ }^{[12]}$. The solid solubility of $\mathrm{MgZn}_{2}$ in $\mathrm{Al}$ is $28 \mathrm{wt} . \%$ at eutectic temperature and $4-5 \mathrm{wt} . \%$ at room temperature ${ }^{[13]}$. Therefore, $\mathrm{Zn}$ is considered a good potential element to improve the properties of 6xxx alloys. Yan L, et al. ${ }^{[14]}$ observed $\eta^{\prime}$ phase and found the improved bake hardening response as $0.6 \mathrm{wt} . \% \mathrm{Zn}$ was added in the Al-Mg-Si alloys with a Si content of 0.85 wt. $\%{ }^{\left[{ }^{[9]} \text {. Wang }\right.}$ $\mathrm{X}$ et al. ${ }^{[15]}$ found that the $\mathrm{Zn}$-free alloy sheet consists mainly of $\mathrm{Cube}_{\mathrm{ND}}, \mathrm{P}$ and Goss orientations, while the sheet with high $\mathrm{Zn}$ content and Si content of $0.9 \mathrm{wt} . \%$ after solution treatment possesses a stronger structure consisting of Cube $\mathrm{ND}_{\mathrm{ND}}$, Cube, $(012)<100>,(113)<392>$ and $(023)<032>$ orientations. The effect of $\mathrm{Zn}$ addition on the precipitate sequence of $\mathrm{Al}-\mathrm{Mg}$-Si alloys was also widely reported $^{[12,13,16]}$. With the increasing of $\mathrm{Zn}$ content, the precipitate sequence of $\mathrm{Al}-\mathrm{Mg}-\mathrm{Si}$ alloys from SSSS $\rightarrow$ atomic clusters $\rightarrow$ GP zones (pre- $\left.\beta^{\prime \prime}\right) \rightarrow \beta^{\prime \prime} \rightarrow \beta^{\prime}, \mathrm{U} 1, \mathrm{U} 2$, $\mathrm{B}^{\prime} \rightarrow \beta$ changed to SSSS $\rightarrow$ atomic clusters $\rightarrow$ GP zones $\left(\right.$ pre- $\left.\beta^{\prime \prime}\right) \rightarrow \beta^{\prime \prime}, \mathrm{L}, \mathrm{S}, \mathrm{C}, \mathrm{QP}, \mathrm{QC} \rightarrow \beta^{\prime} \rightarrow \beta$.

All the research about Al-Mg-Si-Zn was focused on alloys with low $\mathrm{Si}$ contents (less than $0.9 \%$ ). The microstructure and mechanical properties when the Si content is more than $0.9 \%$ remained unclear. The interest of this study is associated with the change of mechanical properties and microstructure of Al-Mg-Si$\mathrm{Zn}$ with more Si addition. In this work, the influence of Si content on the microstructure and properties of Al$\mathrm{Mg}-\mathrm{Si}-\mathrm{Zn}$ alloys were investigated. 


\section{Experimental procedure}

The 6061 raw materials were placed in a graphite crucible and melted in an electrical resistance furnace at $780{ }^{\circ} \mathrm{C}$ for 20 min. After melted completely, the pure magnesium, pure zinc particles and $\mathrm{AlSi}_{12}$ wrapped with aluminum foil were added into the graphite crucible, stirred, then reheated to $780{ }^{\circ} \mathrm{C}$ and held for $10 \mathrm{~min}$. After this, the furnace temperature was lowered to $720{ }^{\circ} \mathrm{C}$ and kept for $5 \mathrm{~min}$. At last, the alloy ingots were cast in a high strength graphite mold, as shown in Fig. 1. The chemical compositions of the experimental Al-Mg-Si-Zn alloys with different Si contents are shown in Table 1.

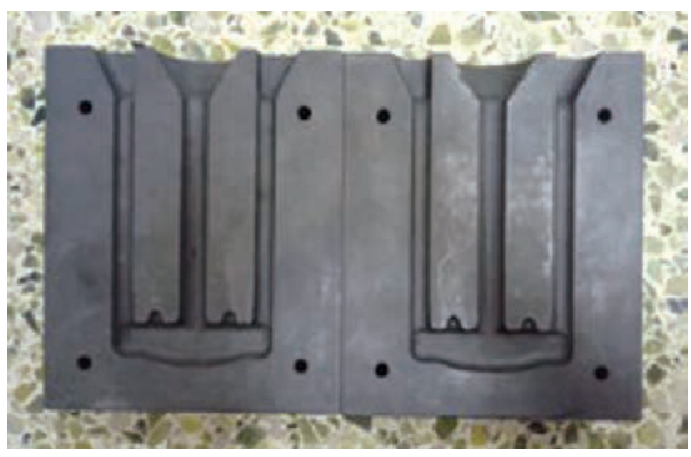

Fig. 1: Profile and geometry of high strength graphite mold

Table 1: Chemical compositions of Al-Mg-Si-Zn samples (wt.\%)

$\begin{array}{cccccccccccc}\text { Alloys } & \text { Si } & \text { Mg } & \text { Zn } & \text { Fe } & \text { Cu } & \text { Mn } & \text { Cr } & \text { Ti } & \text { Al } \\ \# 1 & 0.66 & 1.20 & 2.00 & 0.09 & 0.15 & 0.06 & 0.06 & 0.12 & \text { Bal. } \\ \# 2 & 0.98 & 1.22 & 2.04 & 0.10 & 0.14 & 0.06 & 0.06 & 0.12 & \text { Bal. } \\ \# 3 & 1.50 & 1.17 & 2.03 & 0.11 & 0.15 & 0.06 & 0.06 & 0.11 & \text { Bal. } \\ \# 4 & 1.91 & 1.23 & 2.00 & 0.10 & 0.13 & 0.05 & 0.06 & 0.11 & \text { Bal. } \\ \# 5 & 2.38 & 1.16 & 2.00 & 0.11 & 0.13 & 0.05 & 0.06 & 0.11 & \text { Bal. } \\ \# 6 & 3.12 & 1.18 & 2.05 & 0.12 & 0.12 & 0.05 & 0.05 & 0.10 & \text { Bal. } \\ \# 7 & 3.47 & 1.16 & 2.03 & 0.11 & 0.11 & 0.05 & 0.05 & 0.10 & \text { Bal. } \\ \# 8 & 4.00 & 1.20 & 2.05 & 0.12 & 0.11 & 0.04 & 0.05 & 0.09 & \text { Bal. }\end{array}$

A commercial thermodynamic package (JMatPro) was used to determine the volume change of the aluminum alloy test bar. Microstructure analysis was carried out by a Zeiss Axio Imager A2m optical microscope (OM). The samples for microstructure observation were etched in a $0.5 \% \mathrm{HF}+99.5 \% \mathrm{H}_{2} \mathrm{O}$ solution. The XRD-6100 X-ray diffraction (XRD) was used to identify the phases, interplanar spacing and structure (along the longitudinal direction of the specimen). The second phases were investigated using a JSM-7500F scanning electron microscope (SEM) and an energy dispersive X-ray spectroscope (EDS). The tensile strength and elongation were tested on the CMT5105 electronic universal tensile testing machine.

\section{Results and discussion}

\subsection{Microstructure}

Figure 2 shows the as-cast microstructures of alloys with different additions of Si. As can be seen, the as-cast microstructures show typical hypo-eutectic structure, where the $\alpha-\mathrm{Al}$ exists as cellular grains and the granular and lumpy $\mathrm{Mg}_{2} \mathrm{Si}$ phases distribute in intragranular and grain boundary, as shown in Figs. 1 (a) to (c). With the increasing of $\mathrm{Si}$, eutectic phases begin to appear in the alloys as shown in Fig. 1 (d) to (i). They are plate-like eutectic Si distributing at the grain boundary which make the grain boundary coarsen ${ }^{[17]}$.
The XRD patterns in Fig. 3 indicate that the phases existing in Alloy \#1 are mainly $\mathrm{Mg}_{2} \mathrm{Si}$ and $\mathrm{Mg}_{5} \mathrm{Si}_{6}$. With the increase of $\mathrm{Si}$ content, additional $\mathrm{Si}$ and $\mathrm{Al}_{3.21} \mathrm{Si}_{0.47}$ phases precipitate in the form of Al-Si eutectic phases in the alloys, as shown in the curves of Alloys \#5 and \#9.

To study the effect of Si content on microstructure, the mean shape factor $(S)$ was applied to represent the second phase shape change. The mean shape factor $(S)$ was calculated as follows ${ }^{[18,19]}$.

$$
S=\frac{\sum_{i=1}^{n} A_{i} \frac{2 \sqrt{\pi A_{i}}}{P_{i}}}{\sum_{i=1}^{n} A_{i}}
$$

where $S$ is the mean shape factor; $A_{\mathrm{i}}$ is the area of second phases; $P_{\mathrm{i}}$ is the perimeter of a second phase; $n$ is the number of second phases.

The changes of second phase area fraction $(A)$ and the mean shape factor $(S)$ with Si content $(x)$ are shown in Fig. 4 and Table 2. The correlation coefficient $\left(R^{2}\right)$ was calculated to determine the data correlation.

As shown in Fig. 4, the $S$ increases firstly and then decreases with the increase of Si. With the Si content less than $1.50 \mathrm{wt} . \%$, the morphology of $\mathrm{Si}$ is similar to circular, the same as that reported in Ref. ${ }^{[20]}$, as shown in Points 1 and 2 in Fig. 2 (b, c), which 

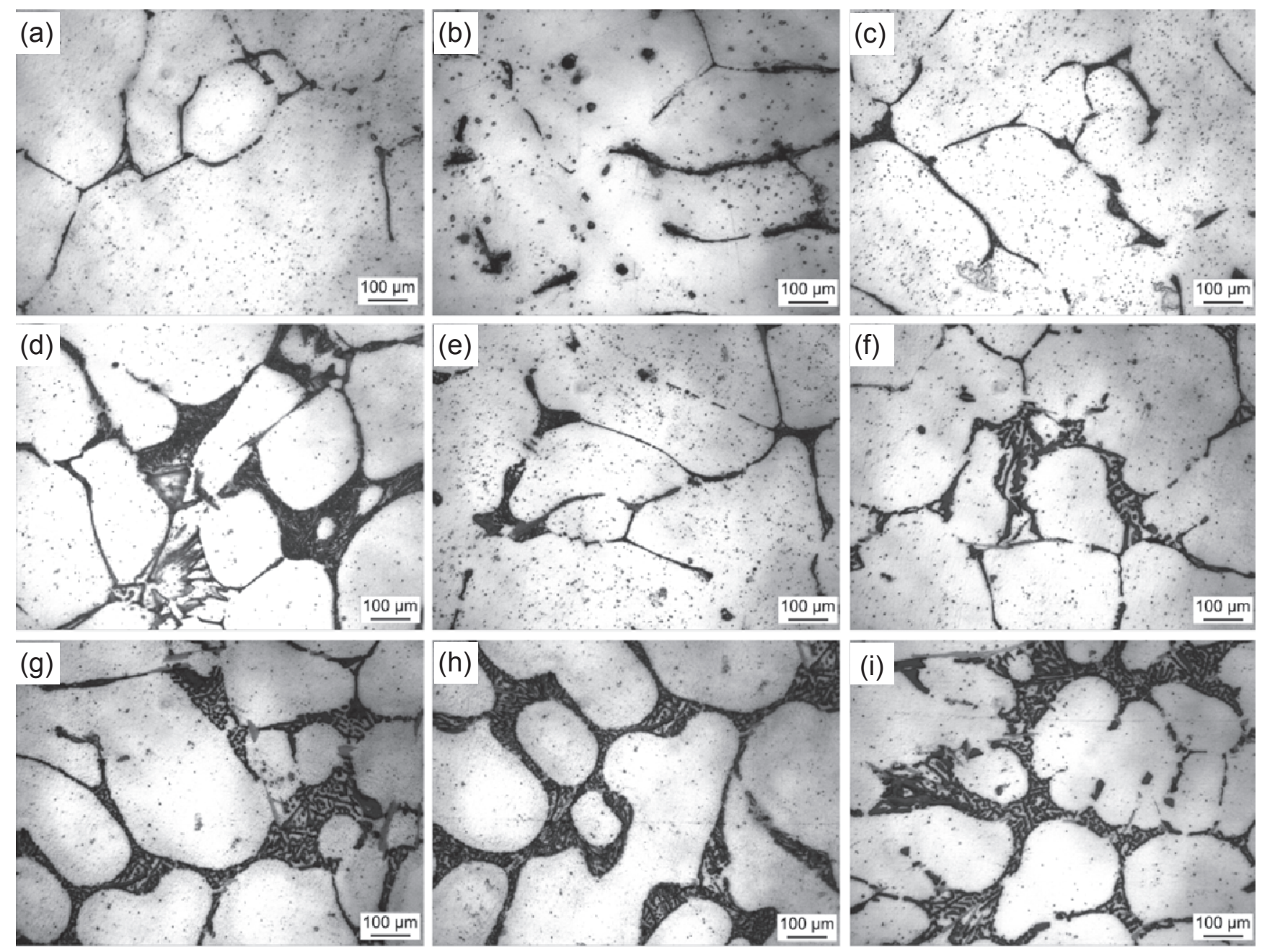

Fig. 2: Microstructures of alloys with different Si contents: (a) Alloy \#1; (b) Alloy \#2; (c) Alloy \#3; (d) Alloy \#4; (e) Alloy \#5; (f) Alloy \#6; (g) Alloy \#7; (h) Alloy \#8; (i) Alloy \#9

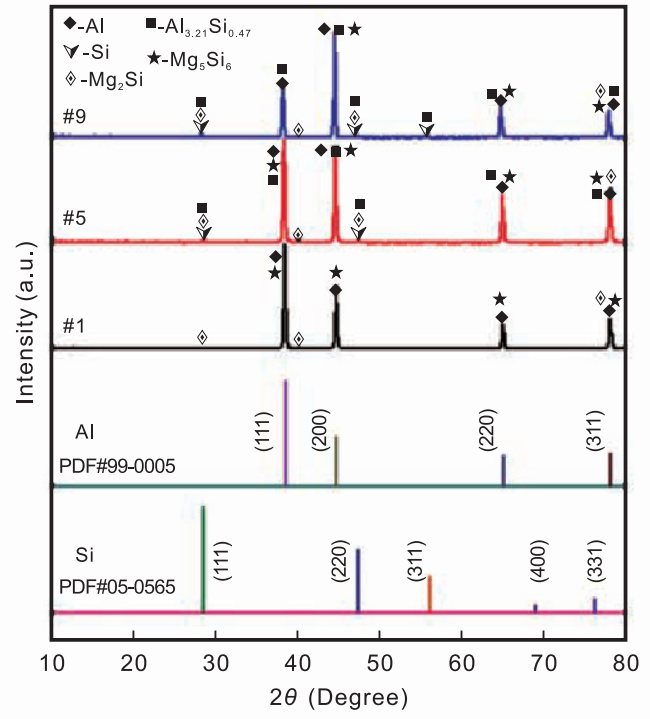

Fig. 3: XRD patterns of as-cast alloys with different $\mathrm{Si}$ contents

led to a greater $S$ value. The maximum solubility of $\mathrm{Si}$ in $\mathrm{Al}$ is $1.65 \mathrm{wt} . \%$. When the $\mathrm{Si}$ content is more than $1.50 \mathrm{wt} . \%$, excess of $\mathrm{Si}$ agglomeration forms plate eutectic structure between $\alpha-\mathrm{Al}$ grains, which reduces the $S$ value correspondingly.

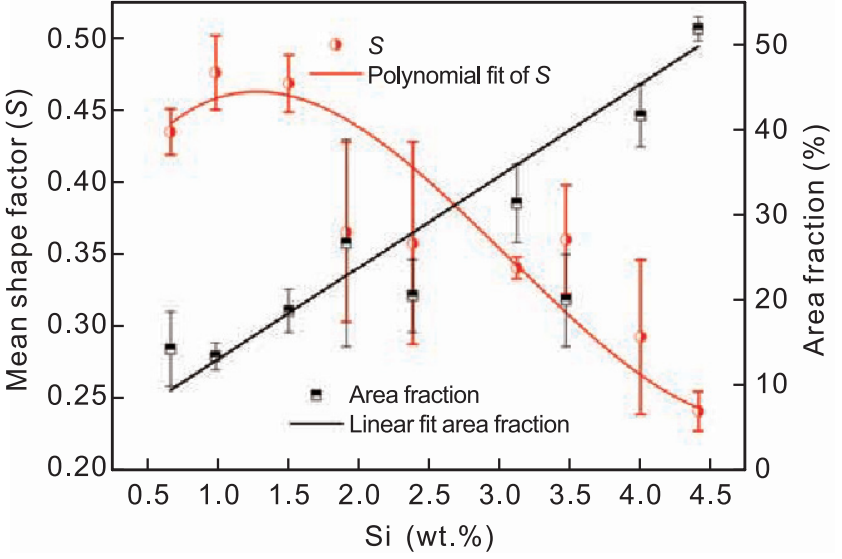

Fig. 4: Change of area fraction $(A)$ of second phases and mean shape factor $(S)$ with different $\mathrm{Si}$ contents

\subsection{Mechanical properties}

Figure 5 shows the tensile strength and elongation of the alloys with different $\mathrm{Si}$ contents. It can be found that, in general, the tensile strength increases, while the elongation decreases with the addition of Si.

The ratio of the peak intensity of the (200) plane to the (111) plane in XRD curves in Fig. 3 was calculated. The results 
Table 2: Calculation results of mean shape factor and area fraction with different Si contents

$\begin{array}{ccc} & \text { Mean shape factor }(\boldsymbol{S}) & \text { Area fraction }(\boldsymbol{A}) \\ \text { Model } & S=\text { intercept }+a x+b x^{2}+c x^{3} & A=\text { intercept }+a x \\ a & 18.55692 & 10.77019 \\ b & -922.06739 & -- \\ c & 10060.46038 & -- \\ \text { intercept } & 0.35474 & 0.0221 \\ R^{2} & 0.94825 & 0.93864\end{array}$

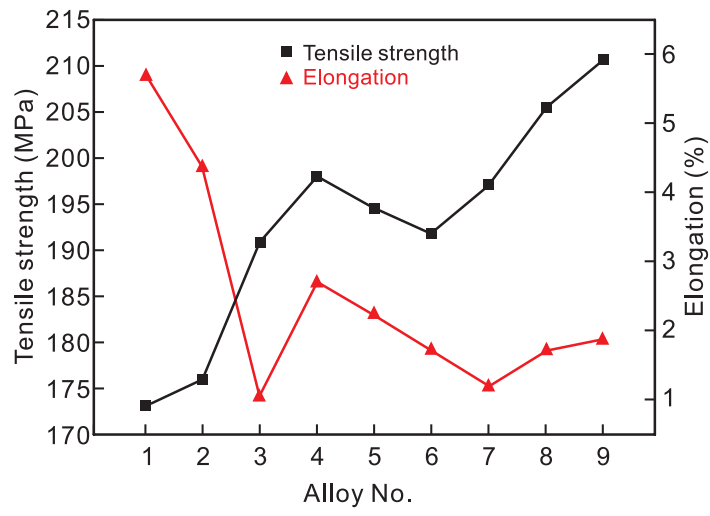

Fig. 5: Tensile strength and elongation of alloys

are shown in Table 3. As compared with pure aluminum, the increasing of Si content leads to an increase of $\mathrm{I}_{(200)} / \mathrm{I}_{(111)}$ value from 0.467 to 2.111 , indicating that the number of $\mathrm{Al}$ (200) structure monotonously increases compared to the $\mathrm{Al}$ (111) structure, which results in the decrease of alloy elongation. It is rather strange that the elongation of Alloy \#3 decreases sharply, which may be related to the precipitation of $\mathrm{Mg}_{2} \mathrm{Si}$. According to Fig. 2, a large amount of granular $\mathrm{Mg}_{2} \mathrm{Si}$ phases precipitate in the intragranular of Alloy \#3 crystal, while the amount of $\mathrm{Mg}_{2} \mathrm{Si}$ phases in the intragranular of the Alloy \#4 decrease significantly, and most of $\mathrm{Mg}_{2} \mathrm{Si}$ phases segregate at the grain boundaries. All of these lead to a lower elongation of Alloy \#3 and a higher elongation of Alloy \#4.

To analyse the effects of the mean shape factor $(S)$, area fraction $(A)$ and the Si content $(x)$ on the tensile strength $(T)$ of the alloys, a mathematic model of multiple linear regressions was established as follows:

$$
T=a x+b S+c A+\text { intercept }
$$

Table 3: Ratio of peak intensity of (200) plane to (111) plane as shown in Fig. 3

$\begin{array}{cr}\text { Samples } & \mathrm{I}_{(200)} / \mathrm{I}_{(111)} \\ \mathrm{Al} & 0.476 \\ \# 1 & 0.519 \\ \# 5 & 0.869 \\ \# 9 & 2.111\end{array}$

By using the regression analysis method, the coefficients $a$, $b, c$ were obtained as shown in Table 4. It can be found that the $\mathrm{Si}$ content has the main influence on tensile strength and the mean shape factor has the least influence on tensile strength.

Table 4: Calculation results based on Eq. (2)

$\begin{array}{cc}T=a x+b S+c A+\text { intercept } & \text { Value } \\ a & 664.86089 \\ b & 12.69124 \\ C & 27.60178 \\ \text { Intercept } & 164.35423 \\ R^{2} & 0.74796\end{array}$

\subsection{Volume change}

Figure 6 shows the appearance of aluminum alloy test bars after casting: the middle column is sprue, and the other two sides are test bars. Figure 6 indicates that the test bars of \#1, \#2 and \#3 got broken as outlined by the red rectangles, while the other test bars have no obvious fractures. This shows that with the increasing of Si content, the volume shrinkage and the shrinkage stress of the alloys decrease.

According to the Bragg equation, the interplanar spacing can be represented as follows:

\section{$2 d \cdot \sin \theta=\lambda$}

where $d$ is the interplanar spacing; $\theta$ is diffraction angle; $\lambda$ is the X-ray wavelength.

Figure 7 shows the interplanar spacings of samples obtained in terms of the XRD curves (Fig. 3). The increasing Si content caused the increase of interplanar spacing between the (111) and (200) planes of Al alloys, but has almost no influence on the interplanar spacing between (220) and (311) planes. The smaller volume change of alloys with high Si content is ascribed to the increased interplanar spacing.

\section{Conclusions}

(1) With the increase of Si content, the mean shape factor of the second phase firstly increases and then decreases.

(2) The regression analysis results show that the Si content has the main influence and the mean shape factor has the least influence on tensile strength. The tensile strength of Al-Mg$\mathrm{Si}-\mathrm{Zn}$ alloy generally increases with the increase of Si content. Compared to the $\mathrm{Al}$ (111) structure of the alloy, the number of Al (200) monotonously increases with the increase of $\mathrm{Si}$ content, which results in reduced elongation.

(3) The interplanar spacings of (111) and (200) crystal planes increase with the increasing of Si content and the volume shrinkage of alloy decreases during the solidification process, so that the alloy with higher Si content does not break easily. 


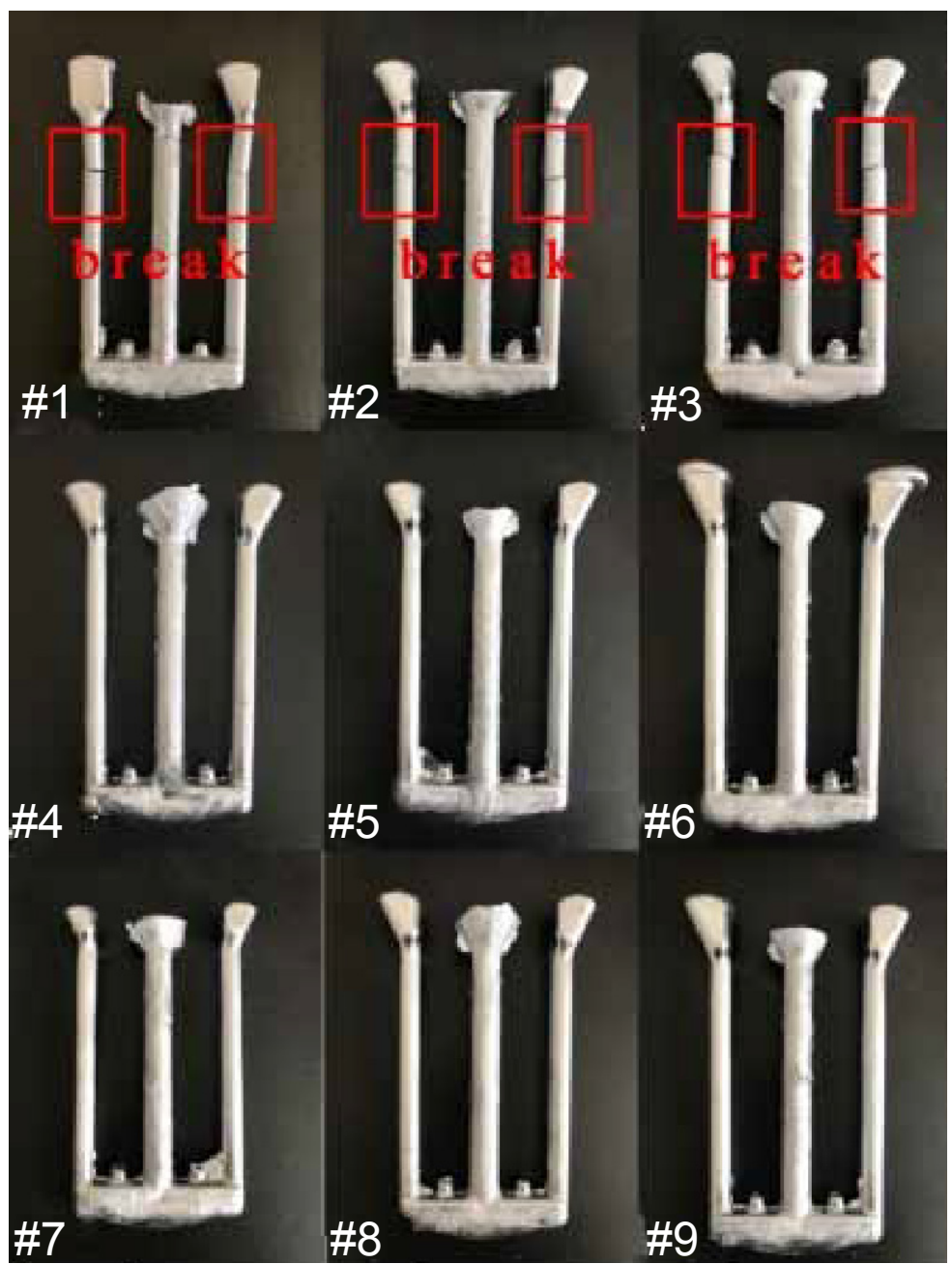

Fig. 6: Photos of samples with different Si contents
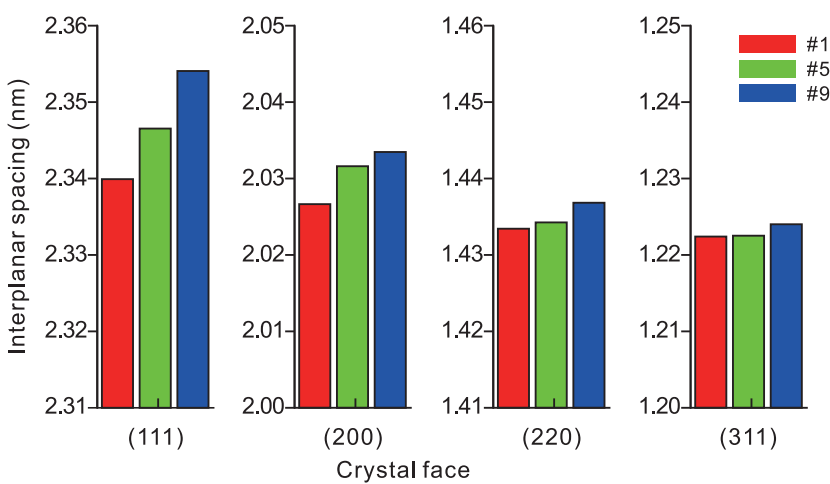

Fig. 7: Interplanar spacings of \#1, \#5 and \#9 alloys

\section{Acknowledgements}

This work was financially supported by the National Natural Science Foundation of China (Grant No. 51875365).

\section{References}

[1] Demir H, Gündüz $\mathrm{S}$. The effects of aging on machinability of 6061 aluminium alloy. Materials and Design, 2009, 30: 1480-1483.
[2] Kim J, Jhang K Y, Kim C. Dependence of nonlinear ultrasonic characteristic on second-phase precipitation in heat-treated $\mathrm{Al}$ 6061-T6 alloy. Ultrasonics, 2017, 82: 84-90.

[3] Ding L, Jia Z, Zhang Z, et al. The natural aging and precipitation hardening behaviour of Al-Mg-Si-Cu alloys with different $\mathrm{Mg} / \mathrm{Si}$ ratios and $\mathrm{Cu}$ additions. Materials Science and Engineering: $\mathrm{A}$, 2015, 627: 119-126.

[4] Xu X, Yang Z, Ye Y, et al. Effects of various Mg/Si ratios on microstructure and performance property of Al-Mg-Si alloy cables. Materials Characterization, 2016, 119: 114-119.

[5] Zhong H, Rometsch P A, Cao L, et al. The influence of Mg/Si ratio and $\mathrm{Cu}$ content on the stretch formability of $6 \mathrm{xxx}$ aluminium alloys. Materials Science and Engineering: A, 2016, 651: 688697.

[6] Tao G H, Liu C H, Chen J H, et al. The influence of Mg/Si ratio on the negative natural aging effect in $\mathrm{Al}-\mathrm{Mg}-\mathrm{Si}-\mathrm{Cu}$ alloys. Materials Science and Engineering: A, 2015, 642: 241-248.

[7] Han Y, Shao D, Chen B A, et al. Effect of Mg/Si ratio on the microstructure and hardness-conductivity relationship of ultrafine-grained Al-Mg-Si alloys. Journal of Materials Science, 2016, 52: 4445-4459.

[8] Gupta A K, Lloyd D J, Court S A. Precipitation hardening in Al$\mathrm{Mg}-\mathrm{Si}$ alloys with and without excess Si. Materials Science and Engineering: A, 2001, 316: 11-17.

[9] Lodgaard L, Ryum N. Precipitation of dispersoids containing Mn and/or $\mathrm{Cr}$ in Al-Mg-Si alloys. Materials Science and Engineering: A, 2000, 283: 144-152. 
[10] Xiao Q, Liu H, Yi D, et al. Effect of Cu content on precipitation and age-hardening behavior in Al-Mg-Si- $x \mathrm{Cu}$ alloys. Journal of Alloys and Compounds, 2017, 695: 1005-1013.

[11] Ding L, Jia Z, Liu Y, et al. The influence of Cu addition and prestraining on the natural aging and bake hardening response of Al-Mg-Si alloys. Journal of Alloys and Compounds, 2016, 688: 362-367.

[12] Saito T, Wenner S, Osmundsen E, et al. The effect of $Z n$ on precipitation in Al-Mg-Si alloys. Philosophical Magazine, 2014, 94: $2410-2425$

[13] Ding $X$ P, Cui $H$, Zhang $J ~ X$, et al. The effect of $Z n$ on the age hardening response in an Al-Mg-Si alloy. Materials and Design, 2015, 65: 1229-1235.

[14] Yan L, Zhang Y, Li X, et al. Effect of Zn addition on microstructure and mechanical properties of an Al-Mg-Si alloy. Progress in Natural Science: Materials International, 2014, 24: 97-100.

[15] Wang X, Guo M X, Zhang J S , et al. Effect of Zn addition on the microstructure, texture evolution and mechanical properties of Al-Mg-Si-Cu alloys. Materials Science \& Engineering A, 2016, 677: 522-533.
[16] Guo M X, Zhang X K, Zhang J S, et al. Effect of Zn addition on the precipitation behaviors of Al-Mg-Si-Cu alloys for automotive applications. Journal of Materials Science, 2016, 52: 13901404.

[17] Prukkanon W, Srisukhumbowornchai N, Limmaneevichitr C. Influence of Sc modification on the fluidity of an A356 aluminum alloy. Journal of Alloys and Compounds, 2009, 487: 453-457.

[18] Prukkanon W, Srisukhumbowornchai N, Limmaneevichitr C. Modification of hypoeutectic Al-Si alloys with scandium. Journal of Alloys and Compounds, 2009, 477: 454-460.

[19] Mao F, Yan G, Xuan Z, et al. Effect of Eu addition on the microstructures and mechanical properties of A356 aluminum alloys. Journal of Alloys and Compounds, 2015, 650: 896-906.

[20] Wang T, Chen X, Luo X, et al. Formation of Si nanoparticle in A matrix for Al-7wt.\%Si alloy during complex shear flow casting. Journal of Alloys and Compounds, 2018, 739: 30-34. 